\title{
Impact of nucleosome dynamics and histone modifications on cell proliferation during Arabidopsis development
}

\author{
B Desvoyes ${ }^{1}$, MP Sanchez ${ }^{1}$, E Ramirez-Parra ${ }^{1}$ and C Gutierrez \\ Centro de Biologia Molecular 'Severo Ochoa', CSIC-UAM, Cantoblanco, Madrid, Spain
}

\begin{abstract}
Eukaryotic chromatin is a highly structured macromolecular complex of which DNA is wrapped around a histone-containing core. DNA can be methylated at specific $C$ residues and each histone molecule can be covalently modified at a large variety of amino acids in both their tail and core domains. Furthermore, nucleosomes are not static entities and both their position and histone composition can also vary. As a consequence, chromatin behaves as a highly dynamic cellular component with a large combinatorial complexity beyond DNA sequence that conforms the epigenetic landscape. This has key consequences on various developmental processes such as
\end{abstract}

root and flower development, gametophyte and embryo formation and response to the environment, among others. Recent evidence indicate that posttranslational modifications of histones also affect cell cycle progression and processes depending on a correct balance of proliferating cell populations, which in the context of a developing organisms includes cell cycle, stem cell dynamics and the exit from the cell cycle to endoreplication and cell differentiation. The impact of epigenetic modifications on these processes will be reviewed here.

Heredity (2010) 105, 80-91; doi:10.1038/hdy.2010.50; published online 28 April 2010

Keywords: cell division cycle; chromatin; epigenetics; differentiation; plant; arabidopsis

\section{Introduction}

The genetic material in eukaryotes is permanently associated with structural proteins (histone and nonhistone proteins) in a high-order and highly compact macromolecular structure called chromatin. The nucleosome is a basic repeating unit of chromatin that consists of $\sim 150$ base pairs of DNA wrapped around a nucleosome core of eight histone molecules (two of each histones $\mathrm{H} 2 \mathrm{~A}, \mathrm{H} 2 \mathrm{~B}, \mathrm{H} 3$ and $\mathrm{H} 4$ ). Histone $\mathrm{H} 1$ binds to non-nucleosomal DNA and contributes to DNA packaging. However, not all nucleosomes are equivalent from a structural and functional point of view. This is due to the presence of some histone variants at specific genomic locations (Ausio, 2006), the occurrence of covalent posttranslational modifications of amino-acid residues (Kouzarides, 2007), and the methylation of certain DNA bases (Weber and Schubeler, 2007). Together, these modifications that do not occur at the DNA sequence level constitute the basis for epigenetic inheritance (Goldberg et al., 2007). Nucleosomes are not static entities and there are macromolecular complexes that stimulate nucleosome sliding, destabilization or disassembly at specific genomic location, thus contributing to modify the positioning relative to the DNA sequence in different cell types or in response to a variety of signals (Clapier

Correspondence: Dr C Gutierrez, Centro de Biologia Molecular 'Severo Ochoa', CSIC-UAM, Nicolas Cabrera 1, Cantoblanco, Madrid 28049, Spain.

E-mail: coutierrez@cbm.uam.es

${ }^{1}$ These authors contributed equally to this work.

Received 30 October 2009; revised 23 March 2010; accepted 25

March 2010; published online 28 April 2010 and Cairns, 2009). These local changes in the fine structure of chromatin crucially affect transcription, DNA replication, DNA repair and, as a consequence, various aspects of cell proliferation dynamics during organogenesis that in plants is largely a postembryonic process that occurs in response to hormonal and developmental cues (Figure 1).

Histones are highly conserved at the amino-acid level. However, one unique aspect of histones is that they can be covalently modified mostly at their N-terminal tails that lie outside the nucleosome core, but also in non-tail locations, inside the nucleosome. Histone residues can be acetylated, methylated, phosphorylated, ubiquitylated, sumoylated, carbonylated and glycated (Kouzarides, 2007). These modifications occur most frequently at lysine residues, but also at arginine, serine and threonine residues. They are normally abbreviated by the histone name, the position that is modified and the nature, for example, ac for acetylation, me for methylation, and number of marks, for example, me3 for trimethylation. The histone $\mathrm{H} 3$ tail is the domain where most of these modifications have been described. These covalent histone modifications are introduced by multiple and highly specific enzymes (Allis et al., 2007; Kouzarides, 2007). For example, some histone acetylases preferentially target a $\mathrm{K}$ residue in histone $\mathrm{H} 3$ but not others, and there are histone methyltransferases that can monomethylate a particular $\mathrm{K}$ residue while a different enzyme is responsible for $\mathrm{di}$ - and/or trymethylation of the same residue. As a consequence, the combinatorial set of histone modifications at a given genomic location, known as the histone code, is extraordinary. Histone modifications can alter chromatin conformation to the 


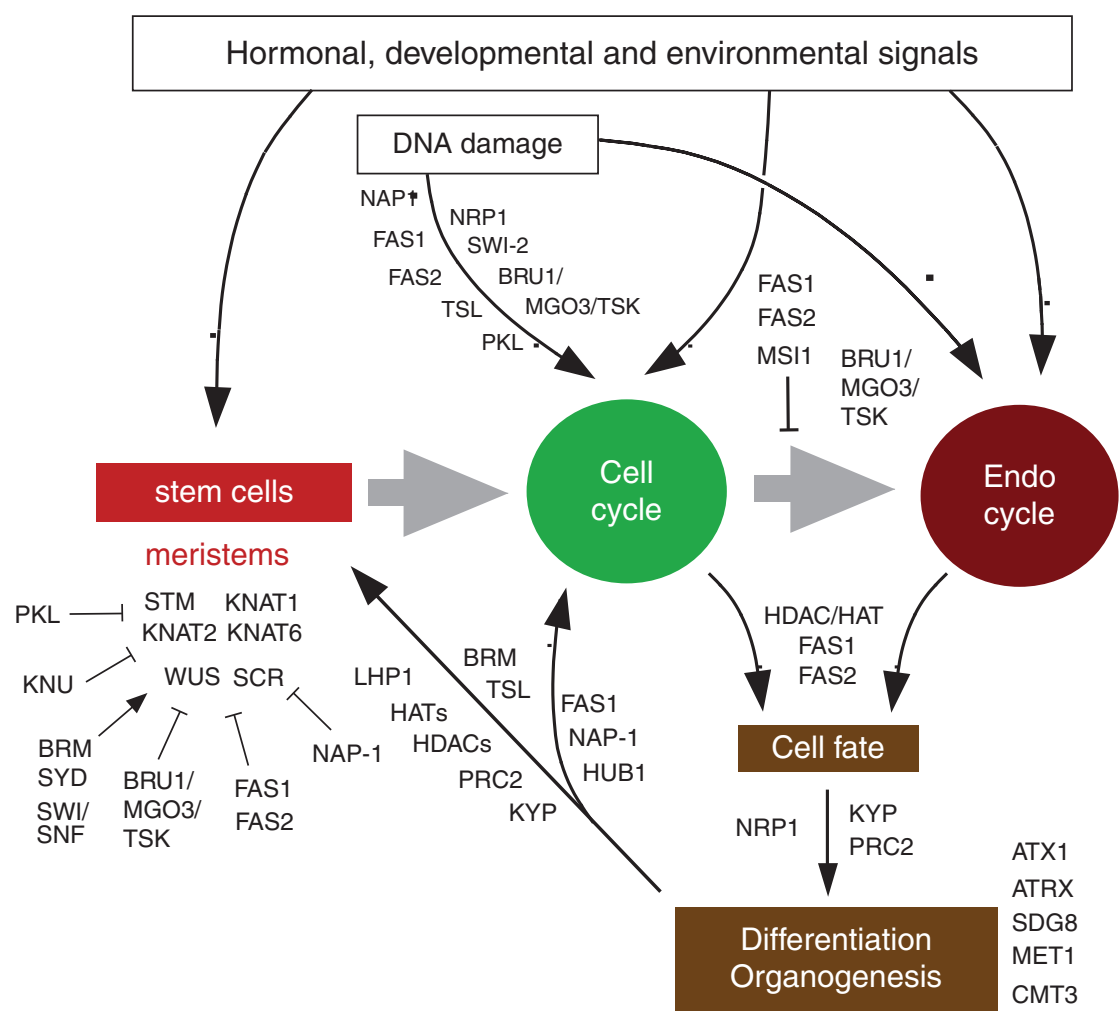

(stem cells, proliferating cells and endoreplicating cells) relevant for organogenesis. Their balance depends on internal (hormonal, developmental) and external (environmental) signals, which in many cases target components of the cell cycle regulatory machinery (Gutierrez, 2005). In addition, DNA damage impinges on the cell division potential through the activity of cell cycle checkpoints that may arrest temporarily the cell cycle or favour the switch to the endocycle. The balance between cell division potential and endoreplication affect cell-fate decisions and, eventually, cell differentiation and organogenesis. A variety of chromatin modifiers have been shown to have a role in these transitions, including the dedifferentiation process.

so-called 'open' or 'closed' states that facilitate or preclude the recruitment of factors required for various processes. Although there are common aspects of the histone code in all organisms, recent evidence show exceptions, as discussed below, which in the case of Arabidopsis contribute to define key differences between the plant and the animal histone code (Fuchs et al., 2006; Sanchez and Gutierrez, 2009b). In any case, we are still very far from fully understanding the histone code and its output in terms of transcriptional control. Thus, one important aspect in decoding the histone code is the role played by effector proteins that specifically recognize certain histone modifications and orchestrate the recruitment of proteins that directly impinge on or have a role in transcriptional regulation. Therefore, the identification of these effector proteins, which ultimately translate the histone code into an activity within a specific biological process, is of primary importance (Henderson and Jacobsen, 2007; Kwon and Wagner, 2007; Matzke et al., 2007; Nelissen et al., 2007; Vaillant and Paszkowski, 2007).

In this review, first we expand these aspects of nucleosome dynamics and epigenetic modifications by describing the enzymes and complexes involved and the modification that they introduce, with emphasis in genomic studies when available. In the final section, we focus on the impact of epigenetic changes in regulating cell proliferation that includes the cell division cycle itself but also the appropriate balance between various cell populations during development, for example, stem cells, dividing cells, endoreplicating cells.

\section{Nucleosome dynamics}

The association of histones with DNA to form mature nucleosomes depends on the action of histone chaperones, which are specialized in incorporating either histones $\mathrm{H} 2 \mathrm{~A}$ and $\mathrm{H} 2 \mathrm{~B}$ or $\mathrm{H} 3$ and $\mathrm{H} 4$ (Polo and Almouzni, 2006).

Histones $\mathrm{H} 2 \mathrm{~A}$ and $\mathrm{H} 2 \mathrm{~B}$ are bound by nucleosome assembly protein-1 (NAP-1) and NAP-related protein (NRP) that function as nuclear-cytoplasmic shuttle chaperones (Galichet and Gruissem, 2006; Zhu et al., 2006). Other nuclear factors such as nucleoplasmin and nucleolin are involved in storage of histone $\mathrm{H} 2 \mathrm{~A}$ and $\mathrm{H} 2 \mathrm{~B}$ or in facilitating histone $\mathrm{H} 2 \mathrm{~A}$ and $\mathrm{H} 2 \mathrm{~B}$ exchange during remodeling of nucleosomes, respectively (Loyola and Almouzni, 2004; Angelov et al., 2006).

The de novo deposition of $\mathrm{H} 3.1 / \mathrm{H} 4$ dimers onto DNA in a DNA synthesis-associated manner during the S-phase or DNA synthesis at the repair sites is facilitated by chromatin assembly factor-1 (CAF-1). CAF-1, a heterotrimeric complex conserved in all eukaryotes (Polo and Almouzni, 2006), is formed in Arabidopsis by the proteins encoded by the FASCIATA1 (FAS1), FASCIATA2 (FAS2) and MULTICOPY SUPPRESSOR OF IRA1 (MSI1) genes, respectively (Leyser and Furner, 1992; Kaya et al., 2001; Hennig et al., 2003). HIRA (histone gene repressor A) 
incorporates the histone variant $\mathrm{H} 3.3$ at any time during the cell cycle or in differentiated cells (Tagami et al., 2004). ASF1 (anti-silencing factor 1) facilitates the assembly mediated by the two $\mathrm{H} 3 / \mathrm{H} 4$ chaperones, CAF-1 and HIRA.

Histone H2A.Z is another histone variant, normally excluded from regions containing methylated DNA (Zilberman et al., 2008) and preferentially deposited by the SWR1/SRCAP ATPase complex (March-Diaz and Reyes, 2009), that is associated with transcriptionally active genes.

SWI/SNF chromatin remodeling complexes, which contribute to the ATP hydrolysis-dependent nucleosome sliding, regulate transcriptional programmes in response to exogenous and endogenous signals. In Arabidopsis, two of these complexes, BRAHMA (BRM) and SPLAYED (SYD), have roles in various developmental settings (Hurtado et al., 2006; Kwon and Wagner, 2007); see also Cell cycle progression)

\section{The machinery of epigenetic modifications}

Histone modification is one of the first steps of the gene expression control cascade by facilitating the recruitment of transcription factors and/or other proteins to chromatin. Among them, acetylation and methylation of various lysine residues in histones $\mathrm{H} 3$ and $\mathrm{H} 4$ are the most studied in relation to transcriptional regulation. In addition, DNA methylation contributes to the silencing of various genomic elements, such as transposons or protein coding genes. We will focus here on those for which a sufficient body of information has been gathered as being relevant for plant cell proliferation.

\section{Histone acetylases and deacetylases}

Acetylation, one of the most frequent histone modifications, is generally associated with transcriptional activation. Plant histone acetyltransferases (HATs) have been classified into four main families on the basis of homology with other eukaryotic HATs. In general, these enzymes modify more than one lysine residue, but some of them have been described to show specificity for particular residues (Allis et al., 2007; Earley et al., 2007).

The HAG subfamily contains GCN5-related N-acetyltransferases. GCN5, which shows a ubiquitous expression pattern, preferentially acetylates histone $\mathrm{H} 3$ at lysine 14 (Benhamed et al., 2006; Earley et al., 2007). HAM subfamily members possess a MYST (MOZ-YBF2/SAS3SAS2-TIP60) domain, of which HAM1 and HAM2 are found in Arabidopsis and possess HAT activity specific for lysine 5 of histone H4 (Earley et al., 2007). Direct evidence for the relevance of this modification in gene expression and/or DNA replication remains to be found. HAM1 and HAM2 are related to HBO1, a human member of this group that binds to the large subunit of the origin recognition complex 1 and other initiation proteins that form pre-replication complexes (Iizuka and Stillman, 1999; lizuka et al., 2006; Miotto and Struhl, 2010). The HAC subfamily members are central integrators of transcriptional regulation and hormonal perception. It is remarkable that, in addition to their ability to acetylate histones, they also use as substrates nonhistone proteins (Pandey et al., 2002). Finally, HAF subfamily members are related to the TATA binding protein-associated factor 1 (Pandey et al., 2002).
Deacetylation frequently correlates with transcriptional repression (Kouzarides, 2007). Arabidopsis histone deacetylases (HDACs) have been classified into three families (Hollender and Liu, 2008; Alinsug et al., 2009). The first one contains members homologous to the yeast RPD3 (reduced potassium deficiency 3) and HDA1 proteins; the second, the HD-tuins (HDT1 through 3), appears to be plant-specific (Wu et al., 2000; Dangl et al., 2001) and the third family contains homologs of the yeast silent information regulator 2 (Sir2), a (NAD)-dependent HDAC (Pandey et al., 2002; Hollender and Liu, 2008). The main conclusion that we can extract from the data available is that a fine balance between HAT and HDAC activities is at the core of crucial processes during plant development.

\section{Histone methylases}

Methylation of lysine residues of histones is carried out by histone methyltransferases (histone KMTases), proteins containing the evolutionary conserved SET (Su(var), E(z), Trithorax) domain (Tschiersch et al., 1994), a 130 amino-acid domain that bears the enzymatic activity (Zhang and Reinberg, 2001). In Arabidopsis, 39 SET domain-containing genes have been identified and classified into six different families, a classification that most likely reflects their substrate specificity ( $\mathrm{Ng}$ et al., 2007). Unlike histone acetylation that is usually associated with gene activation, histone methylation can either repress or activate gene transcription. It can be also associated with eu- or heterochromatin depending on the target residue and the number of methyl groups added. Most studies of Arabidopsis KMTases have been carried out so far with the homologs of the trithorax and Polycomb group (PcG) proteins, originally identified in Drosophila as genes controlling the spatial expression pattern of homeotic genes, and responsible for $\mathrm{H} 3 \mathrm{~K} 4$ and $\mathrm{H} 3 \mathrm{~K} 27$ trimethylation, respectively. In addition, other residues in histones H3 (K9 and K36) and H4 (K20) can be methylated by SET domaincontaining histone KMTases. A distinct class of non-SET domain KMTase, Dot1, has been identified in yeast and animal cells responsible for H3K79 methylation (Feng et al., 2002). The H3K79me has not been identified in Arabidopsis (Zhang et al., 2007a). The identification and functional characterization of the role of individual KMTases is a major effort in the field.

H3K4me: Genome-wide analysis of histone modifications in Arabidopsis has revealed that histone H3 methylation at lysine 4 is present in euchromatin and absent in heterochromatin. $\mathrm{H} 3 \mathrm{~K} 4 \mathrm{me} 3$ and, to a lesser extent, H3K4me2 are associated with actively transcribed genes, whereas H3K4me1 is associated with nonexpressed genes. Although at least one type of $\mathrm{H} 3 \mathrm{~K} 4$ methylation is found in two-thirds of the genes, their distribution is different; $\mathrm{H} 3 \mathrm{~K} 4 \mathrm{me} 2$ and $\mathrm{H} 3 \mathrm{~K} 4 \mathrm{me} 3$ are found predominantly in the promoter and the $5^{\prime}$ end of the open reading frame, whereas $\mathrm{H} 3 \mathrm{~K} 4 \mathrm{me} 1$ is localized within the transcribed region (Zhang et al., 2009).

H3K4 trimethyltransferase activity, a chromatin mark associated with gene activation, has been demonstrated by the best-characterized member of the large trithorax family, the SET domain-containing ARABIDOPSIS HOMOLOG OF TRITHORAX-1 (ATX1) (Alvarez-Venegas and Avramova, 2001; Alvarez-Venegas et al., 2003, 2006; 
Avramova, 2009). ATXR7 is a Set1-related H3K4 methyltransferase that acts in combination with ATX1 to regulate various processes, for example, flowering (Tamada et al., 2009).

H3K4me3 residues are specifically recognized by effector proteins containing a plant homeodomain (Shi et al., 2006; Wysocka et al., 2006; Ruthenburg et al., 2007). Only recently, Arabidopsis proteins containing a plant homeodomain have been identified and among them, ING and Alfin1-like (Lee et al., 2009) and origin recognition complex 1 (Sanchez and Gutierrez, 2009b), which contain an aromaric cage, bind H3K4me3 residues.

H3K27me: Similar to animals, H3K27me3, which is considered the typical signature of PcG protein complex activity, represses gene expression and is introduced by homologs of the Drosophila ENHANCER OF ZESTE (E(Z)) (Muller et al., 2002). In animals, two major types of PcG complexes have been identified: Polycomb Repressive Complex 2 (PRC2) that establishes the repressive state and Polycomb Repressive Complex 1 (PRC1) that maintains it (Schuettengruber and Cavalli, 2009). In Arabidopsis, there are three major PRC2 complexes that differ in their protein composition (Pien and Grossniklaus, 2007; Schatlowski, 2008; Jarillo et al., 2009). They all contain the WD40 proteins FERTILIZATION INDEPENDENT ENDOSPERM (FIE), a homolog of Drosophila Extra Sex Comb, and MSI1 (Ohad et al., 1999; Kohler et al., 2003). The Arabidopsis genome contains three SET domain proteins with methyltransferase activity, MEDEA (MEA), CURLY LEAF (CLF) and SWINGER (SWN), and three homologs of Drosophila Suppressor of Zeste 12 $(\mathrm{Su}(\mathrm{z}) 12)$, which are EMBRYONIC FLOWER 2 (EMF2), FERTILIZATION INDEPENDENT SEED (FIS) and VERNALIZATION 2 (VRN2) (Pien and Grossniklaus, 2007). Their possible relevance in cell proliferation has not been documented.

Maintenance of repressive states in animal cells is achieved by PRC 1 that recognizes the H3K27me3 marks deposited by PRC2 (Schuettengruber and Cavalli, 2009) and induces the ubiquitination of histone H2AK119, a mark that confers a stable gene repression (Wang et al., 2004). In Arabidopsis, H3K $27 \mathrm{me} 3$ is spread along the transcribed regions of genes and more rarely in their promoters (Zhang et al., 2007c). Remarkably, plants lack a homolog of PRC1, but recent evidence suggests that LIKE HETEROCHROMATIN PROTEIN (LHP1), also known as TERMINAL FLOWER 2 (TFL2), could perform this function (Mylne et al., 2006; Turck et al., 2007). In fact, LHP1 (i) associates with H3K27me3 in vitro, (ii) is needed to maintain the stable $\mathrm{H} 3 \mathrm{~K} 27 \mathrm{me} 3$-mediated gene repression in euchromatin (Libault et al., 2005; Nakahigashi et al., 2005) and (iii) although it is not directly involved in histone methylation, disruption of its chromodomain prevents $\mathrm{H} 3 \mathrm{~K} 27 \mathrm{me} 3$ binding and releases silencing of PcG target genes, indicating that LHP1 could be the functional equivalent of PRC1 in plants (Exner and Hennig, 2008). A genome-wide analysis revealed that the LHP1 binding pattern is similar to that of $\mathrm{H} 3 \mathrm{~K} 27 \mathrm{me} 3$ and is mainly present in euchromatin loci, where it colocalizes with H3K27me3 marks (Libault et al., 2005; Turck et al., 2007; Zhang et al., 2007b). However, it must be kept in mind that another PRC1 functional candidate could be
EMBRYONIC FLOWER-1, which maintains the repression of certain genes, for example, AGAMOUS, established by an EMF2-containing PcG complex during vegetative development (Calonje et al., 2008).

Recruitment of PRC1 and PRC2 to their target genes requires the presence of PcG response elements (PREs), which have been identified in Drosophila (Muller and Kassis, 2006). PcG response elements have not been so far identified in Arabidopsis, and the targeting mechanism remains largely unclear. One possibility is that PcGinteracting proteins facilitate PRC2 targeting. Interestingly, the tumor suppressor Retinoblastoma protein $(\mathrm{Rb})$ is necessary to maintain $\mathrm{H} 3 \mathrm{~K} 27$ methylation and PRC2 and PRC1 binding to the promoter of the CDK inhibitor p16 in human cells (Kotake et al., 2007). The plant homolog of human $\mathrm{Rb}$, the RETINOBLASTOMA-RELATED (RBR) protein, binds to FIE (Mosquna et al., 2004) and MSI1 (Ach et al., 1997; Rossi et al., 2001). Although these interactions have not been demonstrated yet in planta, it is tempting to speculate that RBR may be one candidate involved in PRC2 recruitment to the promoter of a subset of target genes.

Recently, it was demonstrated that ATXR5 and ATXR6 proteins display H3K27 monomethyltransferase activity in vitro and in vivo and both are involved in heterochromatin formation and gene silencing (Jacob et al., 2009). They might also contribute to cell cycle regulation, perhaps at some stage during DNA replication, as they interact with the DNA polymerase processivity factor PCNA, and ATXR6 is a target of the E2F transcription factor (Raynaud et al., 2006). Whether a connection between this putative role in cell cycle regulation and heterochromatin formation exists is not known yet.

H3K9me: The KMTase responsible for H3K9me belong to the SUVH family, of which several members have been characterized (Ng et al., 2007). SUVH4, also named KRYPTONITE (KYP), SUVH5 and SUVH6 mediate mono- and dimethylation of $\mathrm{H} 3 \mathrm{~K} 9$ and are required for the nonCG DNA methylation by CMT3 to silence heterochromatic loci and transposons (Jackson et al., 2002; Ebbs and Bender, 2006). In mammalian cells, $\mathrm{H} 3 \mathrm{~K} 9 \mathrm{me} 3$ is a silencing mark when found in the promoter, but is activating when is located within the transcribed regions (Berger, 2007). On the contrary, in Arabidopsis $\mathrm{H} 3 \mathrm{~K} 9 \mathrm{me} 3$ is found in Arabidopsis euchromatin (Fuchs et al., 2006) and active promoters (Caro et al., 2007), whereas H3K9me2 is associated with repressed promoters (Caro et al., 2007; Ramirez-Parra and Gutierrez, 2007a). Genomic analysis has extended these observations and confirmed that the H3K9me3 distribution colocalizes with euchromatin, with a slight bias towards the promoter regions (Turck et al., 2007), whereas $\mathrm{H} 3 \mathrm{~K} 9 \mathrm{me} 2$ is highly enriched in transposons, pseudogenes and repressed genes. It is also associated with pericentromeric regions and with DNA methylation (Bernatavichute et al., 2008), another modification that contributes to chromatin remodeling. SUVH2 is important for the mono- and dimethylation of $\mathrm{H} 3 \mathrm{~K} 9$, but suvh 2 mutant plants also show alterations in monoand dimethyl H3K27 and monomethyl H4K20 levels (Naumann et al., 2005).

H3K36me: On the basis of the homology to the yeast Set2 protein, it is likely that ASHH1, also named SDG8, is 
the KMTase that methylates H3K36 (Ng et al., 2007). Further support comes from the finding of a decreased level of H3K36 methylation at the FLC gene in $s d g 8$ mutant plants (Zhao et al., 2005).

\section{DNA methylases}

DNA methyltransferases covalently attach methyl groups to cytosine. This modification interferes with the binding of the transcriptional machinery to the promoters. Arabidopsis have three types of DNA methyltransferases with different functions: METHYLTRANSFERASE1 (MET1) is the typical maintenance methylase, as it methylates CG sites during DNA replication; CHROMOMETHYLASE3 (CMT3) methylates $\mathrm{CHG}$ (where $\mathrm{H}$ can be $\mathrm{A}, \mathrm{C}$ or $\mathrm{T}$ ) and can initiate de novo methylation, and finally, DOMAINS REARRANGED METHYLTRANSFERASE2 implicated in de novo methylation of $\mathrm{CHH}$ sequences. Their participation in establishing, maintaining and modifying DNA methylation patterns has been recently discussed (Law and Jacobsen, 2010).

\section{Epigenetic pathways involved in cell proliferation dynamics}

The series of processes that enable a cell to produce two daughter cells is known as the cell division cycle. This is the pathway used to increase the population cell number. However, regulation of the number and types of cells within a developing organism is more complex and requires a strict balance between different pools of cells. Thus, some slow-dividing or arrested cells are recruited into the cell division pool, as it is also the case for the first generation of stem cell daughters that moves to the amplifying compartment of meristems to increase cell number. Dividing cells eventually arrest cell cycle, make cell fate decisions and initiate differentiation. In the case of plants, a significant proportion of cells exit the cell cycle to start a different cycle, the endocycle, where cells duplicate their genome in the absence of an intervening mitosis leading to an increase in nuclear DNA content or ploidy level (Caro et al., 2008). As a result, the balance between arrested cells, cycling cells and endoreplicating cells in coordination with cell fate and differentiation pathways constitute one of the crucial aspects controlling organogenesis (Gutierrez, 2005). In this review, we will focus on discussing recent discoveries on the role of various chromatin-related factors in regulating cell proliferation dynamics (Figure 1). The reader is referred to other reviews for details in other processes affected by chromatin modifications (Reyes, 2006; Lodha et al., 2008; Martienssen et al., 2008; Stratmann and Mas, 2008; Gasser and Dean, 2009; Jarillo et al., 2009).

\section{Cell cycle progression}

Cell cycle progression is characterized by a series of unidirectional events that drive a cell from its birth to its division. Some of them depend on the occurrence of cell cycle-specific transcriptional programmes that involve the switch on and off of genes required to progress to the next stage. Extensive chromatin remodeling and histone modifications occur during the cell cycle. For example, transcriptional activation at the G1/S transition, nucleosome deposition during the S-phase, decisions to divide or initiate the endoreplication programme, or chromosome condensation during mitosis, to cite some of the more typical stages. In fact, the expression of some genes encoding proteins required for nucleosome dynamics and histone modifications during the cell cycle are themselves cell cycle regulated (Ramirez-Parra et al., 2003; Vandepoele et al., 2005), for example, they are E2F/DP targets such as the large subunit of CAF-1 (Ramirez-Parra and Gutierrez, 2007a), the HDACs HDT1-4 or the HAM1-2 histone acetyl transferases (Sanchez et al., 2008), among others.

In mammalian cells, the $\mathrm{Rb}$ protein interacts with HDAC either directly (Brehm et al., 1998; MagnaghiJaulin et al., 1998) or indirectly with the help of RbAp48/ MSI1 (Lai et al., 1999). These mechanisms contribute to recruit HDAC to E2F-bound promoters at early G1 and maintain their repressed state (Ferreira et al., 2001; Rayman et al., 2002). Plants seem to share this mechanism, as it has been experimentally demonstrated in maize and tomato (Ach et al., 1997; Nicolas et al., 2001; Rossi et al., 2001; Rossi and Varotto, 2002).

The S-phase is crucial for maintaining epigenetic states because DNA and histones need to be transferred to the daughter chromatin. Newly synthesized DNA is unmethylated and its methylation state needs to be restored every cell cycle (see chapter on DNA methylation in this series). Likewise, newly deposited histones may be unmodified or modified differently from pre-replicative chromatin. S-phase progression seems to be associated with changes in the histone acetylation pattern. In Arabidopsis, H3K18ac and H4K16ac increase during S-phase, although the HATs involved have not been identified. Different modifications occur in other plant species (Fuchs et al., 2006; Sanchez et al., 2008) indicating that, although increase acetylation is a common feature, the nature of these modifications is plant species-specific.

Dimers of acetylated histones $\mathrm{H} 3$ and $\mathrm{H} 4$ are deposited initially by CAF-1 whereas, later on, NAP-1 incorporates histone H2A/H2B dimers (Polo and Almouzni, 2006). CAF-1 is necessary for the maintenance of heterochromatic patterns, although the mechanism is not known. Both fas1 and msi1 mutants possess reduced heterochromatic content and, in general, a less compacted chromatin (Kirik et al., 2006; Schonrock et al., 2006). Also, CAF-1 is necessary to maintain the repressed state of a subset of genes involved in the G2 checkpoint (Endo et al., 2006; Exner et al., 2006; Kirik et al., 2006; Ramirez-Parra and Gutierrez, 2007b). However, instead of a permanent G2 arrest, as it occurs in animal cells, in the absence of CAF1 plant cells trigger a premature switch to the endoreplication programme (Ramirez-Parra and Gutierrez, 2007b). Likewise, NAP1 and NRP are required to avoid a G2 checkpoint arrest (Galichet and Gruissem, 2006; Zhu et al., 2006), although its molecular basis is still unknown (Figure 1).

Histone monoubiquitination seems to be crucial for cell cycle progression. Mutations in the HUB1 (HISTONE MONO-UBIQUITINATION 1) gene that encodes a RING E3 ligase on histone H2B (also known as ang4-1) produce extended cell cycle duration by a decreased expression of several CYCA and CYCB genes, increased expression of G2 marker genes and a premature switch to the endoreplication programme (Fleury et al., 2007). One possible mechanism is through the maintenance of $\mathrm{H} 3 \mathrm{~K} 4 \mathrm{me} 3$, as it has been shown in yeast lacking BRE1, the HUB1 homolog. 
Several histone modifications occur at the onset of mitosis contributing to chromosome condensation. An increase in phosphorylation of histone $\mathrm{H} 3$ at serine 10 (H3S10ph) occurs from early prophase until telophase, a feature common to plants and animals (Hendzel et al., 1997; Cobb et al., 1999; Houben et al., 1999). Phosphorylation of other residues of H3, typically, T3, T11 and S28, also occurs during mitosis and meiosis (Houben et al., 2007). Multiple kinases have been identified in mammalian cells that show $\mathrm{H} 3$ phosphorylation activity (Ito, 2007). The Arabidopsis homologs of AURORA (AUR1-3) kinases are highly expressed in mitosis and can efficiently use $\mathrm{H} 3$ as a substrate, consistent with a role at this stage (Demidov et al., 2005; Kawabe et al., 2005; Kurihara et al., 2006). The TOUSLED (TSL) kinase is expressed at a constant rate during the cell cycle but its activity peaks between late G2/M and the next G1 phase and $\mathrm{H} 3$ is also a known substrate (Figure 1) (Ehsan et al., 2004), although conflicting reports exist regarding the role of TSL on H3 phosphorylation (Wang et al., 2007). Recent evidence in animal cells supports the notion that $\mathrm{H} 3$ phosphorylation is not only involved in chromosome compaction but also in transcriptional regulation. Thus, H3S10ph can increase H3K14ac (Lo et al., 2000) and suppress H3K9ac (Edmondson et al., 2002) and H3K9me (Rea et al., 2000), but information on these functional links in Arabidopsis is lacking.

The end of mitosis and the early G1 of the next cycle are of particular relevance when cells have to take decisions on their fate. At this stage, genes involved in cell-fate decisions and initiation of cell differentiation are maintained in a switched off state or reprogrammed to be active again for the new cell cycle. Such a fine-tuning has been demonstrated using three-dimensional fluorescence in situ hybridization for the homeobox gene GLABRA2 (GL2) that controls cell fate in the Arabidopsis root epidermis (Costa and Shaw, 2006). Fluorescence in situ hybridization signal detected in anaphase nuclei remains during the next G1 in atrichoblasts (cells that will become non-hair cells in the differentiated root epidermis), whereas it is lost in trichoblasts (cells that will become hair cells). This is most likely due to differences in chromatin accessibility to the GL2 locus and is in agreement with the cell cycle-regulated expression of GL2 (Caro et al., 2007). GEM (GL2 expression modulator) is a factor that regulates $\mathrm{H} 3$ acetylation and H3K9 methylation status (Caro et al., 2007), although the histone modifying enzymes involved have not been identified yet. Interestingly, cell-fate decisions facilitated by the decrease in $\mathrm{H} 3$ acetylation and the increase in $\mathrm{H} 3 \mathrm{~K} 9 \mathrm{me} 2$ mediated by GEM at the GL2 locus are taken during the same cell cycle window used to license chromatin for DNA replication (Caro and Gutierrez, 2007). This suggests that these processes might be functionally linked. In support of this, GEM interacts with CDT1 (Caro et al., 2007), a DNA replication protein involved in controlling replication licensing.

Nucleosome remodeling, achieved primarily by SWI/ SNF complexes (Dunaief et al., 1994), is also relevant to regulate the expression of genes required for cell cycle progression. Initial studies in mammalian cells revealed that repressor complexes containing $\mathrm{Rb}, \mathrm{SWI} / \mathrm{SNF}$ and HDAC control cyclin E and cyclin A expression (Zhang et al., 2000). BRM and SYD are plant SWI/SNF complexes, of which BRM is highly expressed in proliferating cells (Farrona et al., 2004). It is not currently known yet whether plant SWI/SNF complexes interact with RBR to regulate cell cycle gene expression.

\section{Cell cycle checkpoints}

The fas 1 and fas 2 mutants present hypersensitivity to genotoxic agents and double-strand break-inducing treatments (Endo et al., 2006; Kirik et al., 2006; Ramirez-Parra and Gutierrez, 2007b). These plants show a constitutively increased amount of double-strand breaks and of the expression of G2 DNA damage checkpoint genes, such as RAD51, PARP1 and BRCA1, in association with an increase in the homologous recombination frequency (Endo et al., 2006; Kirik et al., 2006; Schonrock et al., 2006; Ramirez-Parra and Gutierrez, 2007a). These observations suggest that loss of CAF-1 activity produces defects in chromatin assembly that could lead to genomic instability (Figure 1).

Similar to the fas mutation, loss of function of other histone chaperones also present high sensitivity to DNA damage. Thus, double mutants nrp1 nrp2 are hypersensitive to genotoxic stress, and show increased levels of DNA damage and induction of the repair genes ( $\mathrm{Zhu}$ et al., 2006). Triple mutants nap1;1 nap1;2 nap1;3 show sensitivity to DNA damage produced by UV-C irradiation. In this mutant, the expression levels of genes directly involved in nucleotide excision repair are downregulated (Liu et al., 2009). Constitutive activation of PARP2 expression, high sensitivity to genotoxic stress and increased homologous recombination frequency have been also observed in the brul mutants (Takeda et al., 2004), which have altered stability of heterochromatin organization. The protein kinase TSL phosphorylates the Arabidopsis histone chaperone ASF1 and has a crucial role in the maintenance of transcriptional gene silencing of certain genomic regions. Plants carrying a mutation in the TSL gene present pleiotropic developmental defects and are also more sensitive to UV-B light and methyl methanesulphonate-induced DNA damage (Ehsan et al., 2004; Wang et al., 2007). The study of a selected group of 14 Arabidopsis SWI2/SNF2 genes revealed that 11 of them, including $P K L$ and $B R M$, played a role in DNA damage response (Shaked et al., 2006). Collectively, all these data point to a direct connection between DNA repair and the function of chromatin-modifying factors. Given the continuous presence of DNA damage and DNA replication stress events in proliferating cells, DNA damage response has an important effect on cell cycle progression and, indirectly, in the maintenance of the balance between proliferating cell populations (Figure 1).

\section{Stem cell maintenance in meristems}

Postembryonic development relies almost entirely in apical meristems, whose activity in producing new cells is at the basis of the plant architecture. Thus, the shoot apical meristem (SAM) is responsible for the development of the aerial parts of the plant, whereas the root system depends on the function of the root apical meristem. Both meristems contain a pool of pluripotent stem cells and an amplifying compartment of proliferating cells (Scheres, 2007; Verdeil et al., 2007). In Arabidopsis, several mutations at genes encoding for chromatin factors involved in maintaining epigenetic 
marks through cell division, produce abnormal meristems (Figure 1). These data suggest the crucial role of chromatin remodeling in the establishment and maintenance of the gene expression patterns and the epigenetic status required for the correct meristem function (Goodrich and Tweedie, 2002).

Arabidopsis plants with altered function of CAF-1 (fas1 and fas2 mutants) exhibit defects in the cellular architecture of shoot and root meristems, displaying an aberrant stem cell pool size, suggesting that correct nucleosome deposition during DNA replication is crucial for proper expression of patterning genes. Thus, the expression domains of stem cell-regulatory genes, such as WUSCHEL (WUS), in the SAM, and SCARECROW $(S C R)$, in the root apical meristem, are severely disorganized in the fas1 and fas2 mutants (Kaya et al., 2001). Loss of HIRA function produces developmental defects similar to those observed in plants lacking $A S 1$ function. These plants show increased expression of KNOX genes in developing leaves, suggesting that HIRA is directly involved in maintaining the epigenetic state of KNOX genes, probably by modulating chromatin structure. However, the exact mechanism of HIRA activity at the molecular and cellular level remains unknown (PhelpsDurr et al., 2005). Loss of function of the two H2A/H2B chaperones NRP also has severe effects on root meristem organization associated with deregulated expression of genes involved in root cell proliferation and patterning (Zhu et al., 2006).

Nucleosome remodeling complexes also have a direct role in meristem biology. Arabidopsis BRM is required for vegetative and reproductive development. Thus, the absence of $B R M$ impairs plant growth and reduces the inflorescence meristem and the apical dominance, suggesting that BRM has a role in SAM maintenance (Farrona et al., 2004; Hurtado et al., 2006). SYD is also required for SAM maintenance by directly stimulating WUS expression (Kwon et al., 2005; Kwon and Wagner, 2007). Similar phenotypes were described for mutants in other putative SWI/SNF core complex components. Thus, plants with decreased levels of $B S H$ (for the bushy growth exhibited by mutants), the Arabidopsis SNF5 homolog, present pleiotropic phenotypes with loss of apical dominance and sterility (Brzeski et al., 1999). Arabidopsis swi3a and swi3b mutants are embryonic lethal, whereas the swi3c mutants, but not swi3d mutants, show pleiotropic phenotypes that resemble brm mutants (Sarnowski et al., 2005). PICKLE (PKL) encodes a SWI/ SNF member of the CHD3 family involved in restricting expression of meristematic genes in primordia. The $p k l$ as 1 and $p k l$ as 2 double mutants enhance the phenotype observed in as1 and as 2 mutants, suggesting that $P K L$ cooperated with AS1 and AS2 (ASYMMETRIC LEAVES 2) in the repression of KNOX genes (Ori et al., 2000). This probably seems to be more complex as the HDACs HDT1 and HDT2 also cooperate with AS1 and AS2 to regulate the distribution or generation of miR165/166 to regulate their targets, for example, PHABULOSA (Kidner and Martienssen, 2004).

PICKLE has been also shown to regulate cell identity (Aichinger et al., 2009) by determining the level of H3K27 trimethylation (Zhang et al., 2008). The BRUSHY1 (BRU1)/MGOUN3 (MGO3)/TONSOKU (TSK) gene encodes a protein probably involved in chromatin organization. Surprisingly, bru1 mutants are strikingly similar to fas mutants showing altered phyllotaxy, stem fasciation and shoot and root meristem disorganization with abnormal spatial distribution of WUS gene in shoot meristem (Suzuki et al., 2004; Takeda et al., 2004; Guyomarc'h et al., 2006).

Modification of specific histone residues is also important for a correct expression of genes involved in developmental switches. The pleiotropic effects of gcn5 mutation on plant growth and development suggest that it is required at various developmental stages, for example, the control of floral meristem development by regulating the expression of WUSCHEL (WUS) and AGAMOUS (AG) genes (Bertrand et al., 2003; Vlachonasios et al., 2003). GCN5 and its partner ADA2b regulate stem cell niche maintenance through the PLETHORA (PLT) pathway (Kornet and Scheres, 2009). Additionally, WUS expression in the floral meristem depends on KNUCKLES (KNU), a C2H2-type zinc finger repressor protein whose expression is inhibited by the presence of H3K27me3 marks in the SAM and is later activated by AG to terminate stem cell activity (Sun et al., 2009). This mechanism provides a link between transcriptional feedback and epigenetic modifications during proliferation of stem cells.

\section{Dedifferentiation}

Plants have the remarkable property of being able to regenerate organs from differentiated tissues. Acquisition of the new fate requires an extensive reprogramming of gene expression and is accompanied by changes in chromatin structure (Grafi, 2004). Most studies on the dedifferentiation process have been carried out in a protoplast system. Acquisition of pluripotency occurs during protoplast formation and is characterized by a first phase of chromatin decondensation and disruption of chromocenters, but at this stage cells are not committed yet to any specific fate (Zhao et al., 2001; Tessadori et al., 2007). Further application of the phytohormones auxin and cytokinin is necessary for cells to reenter the cell cycle, proliferate and form a mass of undifferentiated cells, a phase that corresponds with a second phase of chromatin decondensation (Zhao et al., 2001). From these studies it became evident that acquisition of a 'stem cell-like' fate occurs independently of the reactivation of the cell cycle. During the dedifferentiation process, redistribution of LHP1, disruption of the nucleolus and posttranslational modifications of histone $\mathrm{H} 3$ can be evidenced (Williams et al., 2003). The DNA methylation and H3K9me2 patterns, that mark heterochromatin, are not globally altered (Tessadori et al., 2007), but there is a specific reorganization of chromosomal subdomains with reduced DNA methylation that leads to the activation of silent genes (Avivi et al., 2004; Koukalova et al., 2005). The histone methyltransferase mutant kryptonite (kyp/suvh4), with reduced $\mathrm{H} 3 \mathrm{~K} 9 \mathrm{me} 2$, fails to form calli structures, suggesting a role of $\mathrm{H} 3 \mathrm{~K} 9$ methylation in the dedifferentiation and/or proliferation stages (Figure 1). Moreover, this mutant does not present the telomere lengthening, normally associated with the dedifferentiation process (Grafi et al., 2007). Furthermore, there is evidence that a PcG complex is necessary for cellular reprogramming. In fact, clf swn double mutant shows callus-like structures on the leaves that eventually give rise to somatic embryo, 
indicating that PRC2 target genes, which remain unidentified to date, should be activated during the dedifferentiation process (Chanvivattana et al., 2004).

A quite unique situation occurs in a suspension culture of dedifferentiated proliferating cells that cultures can be maintained for years while the cells remain in an undifferentiated state. Euchromatin becomes hypermethylated, whereas heterochromatin undergoes DNA hypomethylation (Tanurdzic et al., 2008). As a consequence, transposon elements become transcriptionally activated in a process mediated by an increase in the amount of a 21nt small interfering RNA species. Moreover, hypermethylation at promoters is associated with histone hypomethylation in undifferentiated cells (Berdasco et al., 2008). These observations reveal the implication of RNA interference, DNA methylation, histone modifications and chromatin remodeling in reprogramming the epigenome of proliferating cultured cells.

\section{Outlook}

The correct balance between sustained cell division, cell cycle arrest and differentiation and exit to the endoreplication programme in different cell populations is crucial for a correct organogenesis. A plethora of genes affecting various aspects of chromatin dynamics have now been shown to be relevant for cell proliferation during Arabidopsis development. Cell cycle regulatory proteins have roles beyond the cell cycle machinery in the maintenance of proliferative competence during plant development (Gutierrez, 2005). In some cases, links to histone modifications have been identified pointing to a functional coordination between cell proliferation and specific epigenetics changes. One aspect of particular relevance is the study of nucleosome dynamics associated with genome replication due to the importance of maintaining epigenetic states after DNA replication both at the DNA and histone level. Thus, the study of the association of cell cycle regulatory proteins and DNA replication factors with nucleosome chaperones, remodeling complexes and histone modification enzymes will be needed to fully understand the impact of epigenetic modifications on organogenesis.

Many of the genes encoding histone-modification enzymes identified in mammalian cells are also present in the Arabidopsis genome. Thus, it is conceivable that most, if not all, histone modifications are common to both animals and plants (Kouzarides, 2007; Pfluger and Wagner, 2007). However, future studies should aim at characterizing functionally the Arabidopsis homologs of chromatin-modifying enzymes, with particular emphasis in the target genes affected and the developmental stages involved. Furthermore, the consequences of certain histone modifications are opposite in animals and plants, suggesting that different mechanisms have evolved to read epigenetic modifications (Fuchs et al., 2006; Sanchez and Gutierrez, 2009a, b). Therefore, the identification and functional study of effector proteins is of primary relevance to advance our understanding of epigenetic changes occurring in different chromatin domains and of the plant histone code.

\section{Conflict of interest}

The authors declare no conflict of interest.

\section{Acknowledgements}

This work has been partially supported by Grants BFU2009-9783, CSD2007-00057-B (Ministry of Science and Innovation), P2006/GEN-0191 (Comunidad de Madrid), and by an institutional grant from Fundación Ramón Areces.

\section{References}

Ach RA, Taranto P, Gruissem W (1997). A conserved family of WD-40 proteins binds to the retinoblastoma protein in both plants and animals. Plant Cell 9: 1595-1606.

Aichinger E, Villar CB, Farrona S, Reyes JC, Hennig L, Kohler C (2009). CHD3 proteins and polycomb group proteins antagonistically determine cell identity in Arabidopsis. PLoS Genet 5: e1000605.

Alinsug MV, Yu CW, Wu K (2009). Phylogenetic analysis, subcellular localization, and expression patterns of RPD3/ HDA1 family histone deacetylases in plants. BMC Plant Biol 9: 37.

Allis CD, Berger SL, Cote J, Dent S, Jenuwien T, Kouzarides T et al. (2007). New nomenclature for chromatin-modifying enzymes. Cell 131: 633-636.

Alvarez-Venegas R, Avramova Z (2001). Two Arabidopsis homologs of the animal trithorax genes: a new structural domain is a signature feature of the trithorax gene family. Gene 271: 215-221.

Alvarez-Venegas R, Pien S, Sadder M, Witmer X, Grossniklaus U, Avramova Z (2003). ATX-1, an Arabidopsis homolog of trithorax, activates flower homeotic genes. Curr Biol 13: 627-637.

Alvarez-Venegas R, Sadder M, Hlavacka A, Baluska F, Xia Y, Lu $\mathrm{G}$ et al. (2006). The Arabidopsis homolog of trithorax, ATX1, binds phosphatidylinositol 5-phosphate, and the two regulate a common set of target genes. Proc Natl Acad Sci USA 103: 6049-6054.

Angelov D, Bondarenko VA, Almagro S, Menoni H, Mongelard F, Hans F et al. (2006). Nucleolin is a histone chaperone with FACT-like activity and assists remodeling of nucleosomes. EMBO J 25: 1669-1679.

Ausio J (2006). Histone variants-the structure behind the function. Brief Funct Genomic Proteomic 5: 228-243.

Avivi Y, Morad V, Ben-Meir H, Zhao J, Kashkush K, Tzfira T et al. (2004). Reorganization of specific chromosomal domains and activation of silent genes in plant cells acquiring pluripotentiality. Dev Dyn 230: 12-22.

Avramova Z (2009). Evolution and pleiotropy of TRITHORAX function in Arabidopsis. Inter J Dev Biol 53: 371-381.

Benhamed M, Bertrand C, Servet C, Zhou DX (2006). Arabidopsis GCN5, HD1, and TAF1/HAF2 interact to regulate histone acetylation required for light-responsive gene expression. Plant Cell 18: 2893-2903.

Berdasco M, Alcazar R, Garcia-Ortiz MV, Ballestar E, Fernandez AF, Roldan-Arjona $\mathrm{T}$ et al. (2008). Promoter DNA hypermethylation and gene repression in undifferentiated Arabidopsis cells. PLoS ONE 3: e3306.

Berger SL (2007). The complex language of chromatin regulation during transcription. Nature 447: 407-412.

Bernatavichute YV, Zhang X, Cokus S, Pellegrini M, Jacobsen SE (2008). Genome-wide association of histone H3 lysine nine methylation with CHG DNA methylation in Arabidopsis thaliana. PLoS ONE 3: e3156.

Bertrand C, Bergounioux C, Domenichini S, Delarue M, Zhou DX (2003). Arabidopsis histone acetyltransferase AtGCN5 regulates the floral meristem activity through the WUSCHEL/ AGAMOUS pathway. J Biol Chem 278: 28246-28251.

Brehm A, Miska EA, McCance DJ, Reid JL, Bannister AJ, Kouzarides T (1998). Retinoblastoma protein recruits histone deacetylase to repress transcription. Nature 391: 597-601. 
Brzeski J, Podstolski W, Olczak K, Jerzmanowski A (1999). Identification and analysis of the Arabidopsis thaliana BSH gene, a member of the SNF5 gene family. Nucleic Acids Res 27: 2393-2399.

Calonje M, Sanchez R, Chen L, Sung ZR (2008). EMBRYONIC FLOWER1 participates in polycomb group-mediated AG gene silencing in Arabidopsis. Plant Cell 20: 277-291.

Caro E, Gutierrez C (2007). A green GEM: intriguing analogies with animal geminin. Trends Cell Biol 17: 580-585.

Caro E, Castellano MM, Gutierrez C (2007). A chromatin link that couples cell division to root epidermis patterning in Arabidopsis. Nature 447: 213-217.

Caro E, Desvoyes B, Ramirez-Parra E, Sanchez Mde L, Gutierrez C (2008). Endoreduplication control during plant development. SEB Exp Biol Series 59: 167-187.

Chanvivattana Y, Bishopp A, Schubert D, Stock C, Moon YH, Sung ZR et al. (2004). Interaction of Polycomb-group proteins controlling flowering in Arabidopsis. Development 131: 5263-5276.

Clapier CR, Cairns BR (2009). The biology of chromatin remodeling complexes. Annu Rev Biochem 78: 273-304.

Cobb J, Miyaike M, Kikuchi A, Handel MA (1999). Meiotic events at the centromeric heterochromatin: histone $\mathrm{H} 3$ phosphorylation, topoisomerase II alpha localization and chromosome condensation. Chromosoma 108: 412-425.

Costa S, Shaw P (2006). Chromatin organization and cell fate switch respond to positional information in Arabidopsis. Nature 439: 493-496.

Dangl M, Brosch G, Haas H, Loidl P, Lusser A (2001). Comparative analysis of HD2 type histone deacetylases in higher plants. Planta 213: 280-285.

Demidov D, Van Damme D, Geelen D, Blattner FR, Houben A (2005). Identification and dynamics of two classes of auroralike kinases in Arabidopsis and other plants. Plant Cell 17: 836-848.

Dunaief JL, Strober BE, Guha S, Khavari PA, Alin K, Luban J et al. (1994). The retinoblastoma protein and BRG1 form a complex and cooperate to induce cell cycle arrest. Cell 79: 119-130.

Earley KW, Shook MS, Brower-Toland B, Hicks L, Pikaard CS (2007). In vitro specificities of Arabidopsis co-activator histone acetyltransferases: implications for histone hyperacetylation in gene activation. Plant J 52: 615-626.

Ebbs ML, Bender J (2006). Locus-specific control of DNA methylation by the Arabidopsis SUVH5 histone methyltransferase. Plant Cell 18: 1166-1176.

Edmondson DG, Davie JK, Zhou J, Mirnikjoo B, Tatchell K, Dent SY (2002). Site-specific loss of acetylation upon phosphorylation of histone H3. J Biol Chem 277: 29496-29502.

Ehsan H, Reichheld JP, Durfee T, Roe JL (2004). TOUSLED kinase activity oscillates during the cell cycle and interacts with chromatin regulators. Plant Physiol 134: 1488-1499.

Endo M, Ishikawa Y, Osakabe K, Nakayama S, Kaya H, Araki T et al. (2006). Increased frequency of homologous recombination and T-DNA integration in Arabidopsis CAF-1 mutants. $E M B O$ J 25: 5579-5590.

Exner V, Hennig L (2008). Chromatin rearrangements in development. Curr Opin Plant Biol 11: 64-69.

Exner V, Taranto P, Schonrock N, Gruissem W, Hennig L (2006). Chromatin assembly factor CAF-1 is required for cellular differentiation during plant development. Development 133: 4163-4172.

Farrona S, Hurtado L, Bowman JL, Reyes JC (2004). The Arabidopsis thaliana SNF2 homolog AtBRM controls shoot development and flowering. Development 131: 4965-4975.

Feng Q, Wang $\mathrm{H}, \mathrm{Ng} \mathrm{HH}$, Erdjument-Bromage $\mathrm{H}$, Tempst $\mathrm{P}$ Struhl K et al. (2002). Methylation of H3-lysine 79 is mediated by a new family of HMTases without a SET domain. Curr Biol 12: 1052-1058.

Ferreira R, Naguibneva I, Mathieu M, Ait-Si-Ali S, Robin P, Pritchard LL et al. (2001). Cell cycle-dependent recruitment of
HDAC-1 correlates with deacetylation of histone $\mathrm{H} 4$ on an Rb-E2F target promoter. EMBO Rep 2: 794-799.

Fleury D, Himanen K, Cnops G, Nelissen H, Boccardi TM, Maere $S$ et al. (2007). The Arabidopsis thaliana homolog of yeast BRE1 has a function in cell cycle regulation during early leaf and root growth. Plant Cell 19: 417-432.

Fuchs J, Demidov D, Houben A, Schubert I (2006). Chromosomal histone modification patterns-from conservation to diversity. Trends Plant Sci 11: 199-208.

Galichet A, Gruissem W (2006). Developmentally controlled farnesylation modulates AtNAP1;1 function in cell proliferation and cell expansion during Arabidopsis leaf development. Plant Physiol 142: 1412-1426.

Gasser CS, Dean C (2009). Growth and development: a broad view of fine detail. Curr Opin Plant Biol 12: 1-3.

Goldberg AD, Allis CD, Bernstein E (2007). Epigenetics: a landscape takes shape. Cell 128: 635-638.

Goodrich J, Tweedie S (2002). Remembrance of things past: chromatin remodeling in plant development. Annu Rev Cell Dev Biol 18: 707-746.

Grafi G (2004). How cells dedifferentiate: a lesson from plants. Dev Biol 268: 1-6.

Grafi G, Ben-Meir H, Avivi Y, Moshe M, Dahan Y, Zemach A (2007). Histone methylation controls telomerase-independent telomere lengthening in cells undergoing dedifferentiation. Dev Biol 306: 838-846.

Gutierrez C (2005). Coupling cell proliferation and development in plants. Nat Cell Biol 7: 535-541.

Guyomarc'h S, Benhamed M, Lemonnier G, Renou JP, Zhou DX, Delarue M (2006). MGOUN3: evidence for chromatin-mediated regulation of FLC expression. J Exp Bot 57: 2111-2119.

Henderson IR, Jacobsen SE (2007). Epigenetic inheritance in plants. Nature 447: 418-424.

Hendzel MJ, Wei Y, Mancini MA, Van Hooser A, Ranalli T, Brinkley BR et al. (1997). Mitosis-specific phosphorylation of histone $\mathrm{H} 3$ initiates primarily within pericentromeric heterochromatin during G2 and spreads in an ordered fashion coincident with mitotic chromosome condensation. Chromosoma 106: 348-360.

Hennig L, Taranto P, Walser M, Schonrock N, Gruissem W (2003). Arabidopsis MSI1 is required for epigenetic maintenance of reproductive development. Development 130: 2555-2565.

Hollender C, Liu Z (2008). Histone deacetylase genes in Arabidopsis development. J Integr Plant Biol 50: 875-885.

Houben A, Demidov D, Caperta AD, Karimi R, Agueci F, Vlasenko L (2007). Phosphorylation of histone H3 in plantsa dynamic affair. Biochim Biophys Acta 1769: 308-315.

Houben A, Wako T, Furushima-Shimogawara R, Presting G, Kunzel G, Schubert II et al. (1999). Short communication: the cell cycle dependent phosphorylation of histone $\mathrm{H3}$ is correlated with the condensation of plant mitotic chromosomes. Plant J 18: 675-679.

Hurtado L, Farrona S, Reyes JC (2006). The putative SWI/SNF complex subunit BRAHMA activates flower homeotic genes in Arabidopsis thaliana. Plant Mol Biol 62: 291-304.

Iizuka M, Stillman B (1999). Histone acetyltransferase HBO1 interacts with the ORC1 subunit of the human initiator protein. J Biol Chem 274: 23027-23034.

lizuka M, Matsui T, Takisawa H, Smith MM (2006). Regulation of replication licensing by acetyltransferase Hbo1. Mol Cell Biol 26: 1098-1108.

Ito $\mathrm{T}$ (2007). Role of histone modification in chromatin dynamics. J Biochem 141: 609-614.

Jackson JP, Lindroth AM, Cao X, Jacobsen SE (2002). Control of CpNpG DNA methylation by the KRYPTONITE histone H3 methyltransferase. Nature 416: 556-560.

Jacob Y, Feng S, LeBlanc CA, Bernatavichute YV, Stroud H, Cokus $S$ et al. (2009). ATXR5 and ATXR6 are H3K27 monomethyltransferases required for chromatin structure and gene silencing. Nat Struct Mol Biol 16: 763-768. 
Jarillo JA, Pineiro M, Cubas P, Martinez-Zapater JM (2009). Chromatin remodeling in plant development. Inter J Dev Biol 53: 1581-1596.

Kawabe A, Matsunaga S, Nakagawa K, Kurihara D, Yoneda A, Hasezawa S et al. (2005). Characterization of plant Aurora kinases during mitosis. Plant Mol Biol 58: 1-13.

Kaya H, Shibahara KI, Taoka KI, Iwabuchi M, Stillman B, Araki T (2001). FASCIATA genes for chromatin assembly factor-1 in arabidopsis maintain the cellular organization of apical meristems. Cell 104: 131-142.

Kidner CA, Martienssen RA (2004). Spatially restricted microRNA directs leaf polarity through ARGONAUTE1. Nature 428: 81-84.

Kirik A, Pecinka A, Wendeler E, Reiss B (2006). The chromatin assembly factor subunit FASCIATA1 is involved in homologous recombination in plants. Plant Cell 18: 2431-2442.

Kohler C, Hennig L, Bouveret R, Gheyselinck J, Grossniklaus U, Gruissem W (2003). Arabidopsis MSI1 is a component of the MEA/FIE Polycomb group complex and required for seed development. EMBO J 22: 4804-4814.

Kornet N, Scheres B (2009). Members of the GCN5 histone acetyltransferase complex regulate PLETHORA-mediated root stem cell niche maintenance and transit amplifying cell proliferation in Arabidopsis. Plant Cell 21: 1070-1079.

Kotake Y, Cao R, Viatour P, Sage J, Zhang Y, Xiong Y (2007). pRB family proteins are required for H3K27 trimethylation and Polycomb repression complexes binding to and silencing p16INK4alpha tumor suppressor gene. Genes Dev 21: 49-54.

Koukalova B, Fojtova M, Lim KY, Fulnecek J, Leitch AR, Kovarik A (2005). Dedifferentiation of tobacco cells is associated with ribosomal RNA gene hypomethylation, increased transcription, and chromatin alterations. Plant Physiol 139: 275-286.

Kouzarides T (2007). Chromatin modifications and their function. Cell 128: 693-705.

Kurihara D, Matsunaga S, Kawabe A, Fujimoto S, Noda M, Uchiyama $S$ et al. (2006). Aurora kinase is required for chromosome segregation in tobacco BY-2 cells. Plant $J$ 48: 572-580.

Kwon CS, Wagner D (2007). Unwinding chromatin for development and growth: a few genes at a time. Trends Genet 23: 403-412.

Kwon CS, Chen C, Wagner D (2005). WUSCHEL is a primary target for transcriptional regulation by SPLAYED in dynamic control of stem cell fate in Arabidopsis. Genes Dev 19: 992-1003.

Lai A, Lee JM, Yang WM, DeCaprio JA, Kaelin Jr WG, Seto E et al. (1999). RBP1 recruits both histone deacetylase-dependent and -independent repression activities to retinoblastoma family proteins. Mol Cell Biol 19: 6632-6641.

Law JA, Jacobsen SE (2010). Establishing, maintaining and modifying DNA methylation patterns in plants and animals. Nat Rev Genet 11: 204-220.

Lee WY, Lee D, Chung WI, Kwon CS (2009). Arabidopsis ING and Alfin1-like protein families localize to the nucleus and bind to H3K4me $3 / 2$ via plant homeodomain fingers. Plant J 58: 511-524.

Leyser H, Furner I (1992). Characterisation of three shoot apical meristem mutants of Arabidopsis thaliana. Development 116: 397-403.

Libault M, Tessadori F, Germann S, Snijder B, Fransz P, Gaudin V (2005). The Arabidopsis LHP1 protein is a component of euchromatin. Planta 222: 910-925.

Liu Z, Zhu Y, Gao J, Yu F, Dong A, Shen WH (2009). Molecular and reverse genetic characterization of NUCLEOSOME ASSEMBLY PROTEIN1 (NAP1) genes unravels their function in transcription and nucleotide excision repair in Arabidopsis thaliana. Plant J 59: 27-38.

Lo WS, Trievel RC, Rojas JR, Duggan L, Hsu JY, Allis CD et al. (2000). Phosphorylation of serine 10 in histone H3 is functionally linked in vitro and in vivo to Gcn5-mediated acetylation at lysine 14. Mol Cell 5: 917-926.
Lodha M, Marco CF, Timmermans MC (2008). Genetic and epigenetic regulation of stem cell homeostasis in plants. Cold Spring Harbor Symp Quant Biol 73: 243-251.

Loyola A, Almouzni G (2004). Histone chaperones, a supporting role in the limelight. Biochim Biophys Acta 1677: 3-11.

Magnaghi-Jaulin L, Groisman R, Naguibneva I, Robin P, Lorain S, Le Villain JP et al. (1998). Retinoblastoma protein represses transcription by recruiting a histone deacetylase. Nature 391: 601-605.

March-Diaz R, Reyes JC (2009). The beauty of being a variant: H2A.Z and the SWR1 complex in plants. Mol Plant 2: 565-577.

Martienssen RA, Kloc A, Slotkin RK, Tanurdzic M (2008). Epigenetic inheritance and reprogramming in plants and fission yeast. Cold Spring Harbor Symp Quant Biol 73: 265-271.

Matzke M, Kanno T, Huettel B, Daxinger L, Matzke AJ (2007). Targets of RNA-directed DNA methylation. Curr Opin Plant Biol 10: 512-519.

Miotto B, Struhl K (2010). HBO1 Histone acetylase activity is essential for DNA replication licensing and inhibited by geminin. Mol Cell 37: 57-66.

Mosquna A, Katz A, Shochat S, Grafi G, Ohad N (2004). Interaction of FIE, a polycomb protein, with pRb: a possible mechanism regulating endosperm development. Mol Genet Genomics 271: 651-657.

Muller J, Kassis JA (2006). Polycomb response elements and targeting of Polycomb group proteins in Drosophila. Curr Opin Genet Dev 16: 476-484.

Muller J, Hart CM, Francis NJ, Vargas ML, Sengupta A, Wild B et al. (2002). Histone methyltransferase activity of a Drosophila Polycomb group repressor complex. Cell 111: 197-208.

Mylne JS, Barrett L, Tessadori F, Mesnage S, Johnson L, Bernatavichute YV et al. (2006). LHP1, the Arabidopsis homologue of HETEROCHROMATIN PROTEIN1, is required for epigenetic silencing of FLC. Proc Natl Acad Sci USA 103: 5012-5017.

Nakahigashi K, Jasencakova Z, Schubert I, Goto K (2005). The Arabidopsis heterochromatin protein1 homolog (TERMINAL FLOWER2) silences genes within the euchromatic region but not genes positioned in heterochromatin. Plant Cell Physiol 46: 1747-1756.

Naumann K, Fischer A, Hofmann I, Krauss V, Phalke S, Irmler $\mathrm{K}$ et al. (2005). Pivotal role of AtSUVH2 in heterochromatic histone methylation and gene silencing in Arabidopsis. EMBO J 24: 1418-1429.

Nelissen H, Boccardi MT, Himanen K, Van Lijsebettens M (2007). Impact of core histone modifications on transcriptional regulation and plant growth. Crit Rev Plant Sci 26: 243-263.

Ng DW, Wang T, Chandrasekharan MB, Aramayo R, Kertbundit S, Hall TC (2007). Plant SET domain-containing proteins: structure, function and regulation. Biochim Biophys Acta 1769: 316-329.

Nicolas E, Ait-Si-Ali S, Trouche D (2001). The histone deacetylase HDAC3 targets RbAp48 to the retinoblastoma protein. Nucleic Acids Res 29: 3131-3136.

Ohad N, Yadegari R, Margossian L, Hannon M, Michaeli D, Harada JJ et al. (1999). Mutations in FIE, a WD polycomb group gene, allow endosperm development without fertilization. Plant Cell 11: 407-416.

Ori N, Eshed Y, Chuck G, Bowman JL, Hake S (2000). Mechanisms that control knox gene expression in the Arabidopsis shoot. Development 127: 5523-5532.

Pandey R, Muller A, Napoli CA, Selinger DA, Pikaard CS, Richards EJ et al. (2002). Analysis of histone acetyltransferase and histone deacetylase families of Arabidopsis thaliana suggests functional diversification of chromatin modification among multicellular eukaryotes. Nucleic Acids Res 30: 5036-5055.

Pfluger J, Wagner D (2007). Histone modifications and dynamic regulation of genome accessibility in plants. Curr Opin Plant Biol 10: 645-652. 
Phelps-Durr TL, Thomas J, Vahab P, Timmermans MC (2005). Maize rough sheath2 and its Arabidopsis orthologue ASYMMETRIC LEAVES1 interact with HIRA, a predicted histone chaperone, to maintain knox gene silencing and determinacy during organogenesis. Plant Cell 17: 2886-2898.

Pien S, Grossniklaus U (2007). Polycomb group and trithorax group proteins in Arabidopsis. Biochim Biophys Acta 1769: 375-382.

Polo SE, Almouzni G (2006). Chromatin assembly: a basic recipe with various flavours. Curr Opin Genet Dev 16: 104-111.

Ramirez-Parra E, Gutierrez C (2007a). E2F regulates FASCIATA1, a chromatin assembly gene whose loss switches on the endocycle and activates gene expression by changing the epigenetic status. Plant Physiol 144: 105-120.

Ramirez-Parra E, Gutierrez C (2007b). The many faces of chromatin assembly factor 1 . Trends Plant Sci 12: 570-576.

Ramirez-Parra E, Frundt C, Gutierrez C (2003). A genome-wide identification of E2F-regulated genes in Arabidopsis. Plant J 33: 801-811.

Rayman JB, Takahashi Y, Indjeian VB, Dannenberg JH, Catchpole S, Watson RJ et al. (2002). E2F mediates cell cycle-dependent transcriptional repression in vivo by recruitment of an HDAC $1 / \mathrm{mSin} 3 \mathrm{~B}$ corepressor complex. Genes Dev 16: 933-947.

Raynaud C, Sozzani R, Glab N, Domenichini S, Perennes C, Cella $\mathrm{R}$ et al. (2006). Two cell-cycle regulated SET-domain proteins interact with proliferating cell nuclear antigen (PCNA) in Arabidopsis. Plant J 47: 395-407.

Rea S, Eisenhaber F, O'Carroll D, Strahl BD, Sun ZW, Schmid M et al. (2000). Regulation of chromatin structure by site-specific histone H3 methyltransferases. Nature 406: 593-599.

Reyes JC (2006). Chromatin modifiers that control plant development. Curr Opin Plant Biol 9: 21-27.

Rossi V, Varotto S (2002). Insights into the G1/S transition in plants. Planta 215: 345-356.

Rossi V, Varotto S, Locatelli S, Lanzanova C, Lauria M, Zanotti E et al. (2001). The maize WD-repeat gene $\mathrm{ZmRbAp} 1$ encodes a member of the MSI/RbAp sub-family and is differentially expressed during endosperm development. Mol Genet Genomics 265: 576-584.

Ruthenburg AJ, Allis CD, Wysocka J (2007). Methylation of lysine 4 on histone H3: intricacy of writing and reading a single epigenetic mark. Mol Cell 25: 15-30.

Sanchez M, Caro E, Desvoyes B, Ramirez-Parra E, Gutierrez C (2008). Chromatin dynamics during the plant cell cycle. Semin Cell Dev Biol 19: 537-546.

Sanchez MP, Gutierrez C (2009a). Novel insights into the plant histone code: lessons from ORC1. Epigenetics 4: 205-208.

Sanchez MP, Gutierrez C (2009b). Arabidopsis ORC1 is a PHDcontaining H3K4me3 effector that regulates transcription. Proc Natl Acad Sci USA 106: 2065-2070.

Sarnowski TJ, Rios G, Jasik J, Swiezewski S, Kaczanowski S, Li $Y$ et al. (2005). SWI3 subunits of putative SWI/SNF chromatin-remodeling complexes play distinct roles during Arabidopsis development. Plant Cell 17: 2454-2472.

Schatlowski N, Creasey K, Goodrich J, Schubert D (2008). Keeping plants in shape: polycomb-group genes and histone methylation. Semin Cell Dev Biol 19:547-553

Scheres B (2007). Stem-cell niches: nursery rhymes across kingdoms. Nat Rev 8: 345-354.

Schonrock N, Exner V, Probst A, Gruissem W, Hennig L (2006). Functional genomic analysis of CAF-1 mutants in Arabidopsis thaliana. J Biol Chem 281: 9560-9568.

Schuettengruber B, Cavalli G (2009). Recruitment of polycomb group complexes and their role in the dynamic regulation of cell fate choice. Development 136: 3531-3542.

Shaked H, Avivi-Ragolsky N, Levy AA (2006). Involvement of the Arabidopsis SWI2/SNF2 chromatin remodeling gene family in DNA damage response and recombination. Genetics 173: 985-994.
Shi X, Hong T, Walter KL, Ewalt M, Michishita E, Hung Tet al. (2006). ING2 PHD domain links histone H3 lysine 4 methylation to active gene repression. Nature 442: 96-99.

Stratmann T, Mas P (2008). Chromatin, photoperiod and the Arabidopsis circadian clock: a question of time. Semin Cell Dev Biol 19: 554-559.

Sun B, Xu Y, Ng KH, Ito T (2009). A timing mechanism for stem cell maintenance and differentiation in the Arabidopsis floral meristem. Genes Dev 23: 1791-1804.

Suzuki T, Inagaki S, Nakajima S, Akashi T, Ohto MA, Kobayashi $\mathrm{M}$ et al. (2004). A novel Arabidopsis gene TONSOKU is required for proper cell arrangement in root and shoot apical meristems. Plant J 38: 673-684.

Tagami H, Ray-Gallet D, Almouzni G, Nakatani Y (2004). Histone H3.1 and H3.3 complexes mediate nucleosome assembly pathways dependent or independent of DNA synthesis. Cell 116: 51-61.

Takeda S, Tadele Z, Hofmann I, Probst AV, Angelis KJ, Kaya H et al. (2004). BRU1, a novel link between responses to DNA damage and epigenetic gene silencing in Arabidopsis. Genes Dev 18: 782-793.

Tamada Y, Yun JY, Woo SC, Amasino RM (2009). ARABIDOPSIS TRITHORAX-RELATED7 is required for methylation of lysine 4 of histone $\mathrm{H} 3$ and for transcriptional activation of FLOWERING LOCUS C. Plant Cell 21: 3257-3269.

Tanurdzic M, Vaughn MW, Jiang H, Lee TJ, Slotkin RK, Sosinski B et al. (2008). Epigenomic consequences of immortalized plant cell suspension culture. PLoS Biol 6: 2880-2895.

Tessadori F, Chupeau MC, Chupeau Y, Knip M, Germann S, van Driel R et al. (2007). Large-scale dissociation and sequential reassembly of pericentric heterochromatin in dedifferentiated Arabidopsis cells. J Cell Sci 120: 1200-1208.

Tschiersch B, Hofmann A, Krauss V, Dorn R, Korge G, Reuter G (1994). The protein encoded by the Drosophila position-effect variegation suppressor gene Su(var)3-9 combines domains of antagonistic regulators of homeotic gene complexes. EMBO J 13: 3822-3831.

Turck F, Roudier F, Farrona S, Martin-Magniette ML, Guillaume E, Buisine N et al. (2007). Arabidopsis TFL2/LHP1 specifically associates with genes marked by trimethylation of histone H3 lysine 27. PLoS Genet 3: e86.

Vaillant I, Paszkowski J (2007). Role of histone and DNA methylation in gene regulation. Curr Opin Plant Biol 10: 528-533.

Vandepoele K, Vlieghe K, Florquin K, Hennig L, Beemster GT, Gruissem W et al. (2005). Genome-wide identification of potential plant E2F target genes. Plant Physiol 139: 316-328.

Verdeil JL, Alemanno L, Niemenak N, Tranbarger TJ (2007). Pluripotent versus totipotent plant stem cells: dependence versus autonomy? Trends Plant Sci 12: 245-252.

Vlachonasios KE, Thomashow MF, Triezenberg SJ (2003). Disruption mutations of ADA2b and GCN5 transcriptional adaptor genes dramatically affect Arabidopsis growth, development, and gene expression. Plant Cell 15: 626-638.

Wang H, Wang L, Erdjument-Bromage H, Vidal M, Tempst P, Jones RS et al. (2004). Role of histone H2A ubiquitination in Polycomb silencing. Nature 431: 873-878.

Wang Y, Liu J, Xia R, Wang J, Shen J, Cao R et al. (2007). The protein kinase TOUSLED is required for maintenance of transcriptional gene silencing in Arabidopsis. EMBO Rep 8: 77-83.

Weber M, Schubeler D (2007). Genomic patterns of DNA methylation: targets and function of an epigenetic mark. Curr Opin Cell Biol 19: 273-280.

Williams L, Zhao J, Morozova N, Li Y, Avivi Y, Grafi G (2003). Chromatin reorganization accompanying cellular dedifferentiation is associated with modifications of histone $\mathrm{H} 3$, redistribution of HP1, and activation of E2F-target genes. Dev Dyn 228: 113-120. 
Wu K, Tian L, Malik K, Brown D, Miki B (2000). Functional analysis of HD2 histone deacetylase homologues in Arabidopsis thaliana. Plant J 22: 19-27.

Wysocka J, Swigut T, Xiao H, Milne TA, Kwon SY, Landry J et al. (2006). A PHD finger of NURF couples histone H3 lysine 4 trimethylation with chromatin remodelling. Nature 442: 86-90.

Zhang H, Rider Jr SD, Henderson JT, Fountain M, Chuang K, Kandachar V et al. (2008). The CHD3 remodeler PICKLE promotes trimethylation of histone $\mathrm{H} 3$ lysine 27. J Biol Chem 283: 22637-22648.

Zhang HS, Gavin M, Dahiya A, Postigo AA, Ma D, Luo RX et al. (2000). Exit from G1 and S phase of the cell cycle is regulated by repressor complexes containing HDAC-Rb-hSWI/SNF and Rb-hSWI/SNF. Cell 101: 79-89.

Zhang K, Sridhar VV, Zhu J, Kapoor A, Zhu JK (2007a). Distinctive core histone post-translational modification patterns in Arabidopsis thaliana. PLoS ONE 2: e1210.

Zhang X, Bernatavichute YV, Cokus S, Pellegrini M, Jacobsen SE (2009). Genome-wide analysis of mono-, di- and trimethylation of histone $\mathrm{H} 3$ lysine 4 in Arabidopsis thaliana. Genome Biol 10: R62.

Zhang X, Germann S, Blus BJ, Khorasanizadeh S, Gaudin V, Jacobsen SE (2007b). The Arabidopsis LHP1 protein coloca- lizes with histone H3 Lys27 trimethylation. Nat Struct Mol Biol 14: 869-871.

Zhang X, Clarenz O, Cokus S, Bernatavichute YV, Pellegrini M, Goodrich J et al. (2007c). Whole-genome analysis of histone H3 lysine 27 trimethylation in Arabidopsis. PLoS Biol 5: e129.

Zhang Y, Reinberg D (2001). Transcription regulation by histone methylation: interplay between different covalent modifications of the core histone tails. Genes Dev 15: 2343-2360.

Zhao J, Morozova N, Williams L, Libs L, Avivi Y, Grafi G (2001). Two phases of chromatin decondensation during dedifferentiation of plant cells: distinction between competence for cell fate switch and a commitment for S phase. J Biol Chem 276: 22772-22778.

Zhao Z, Yu Y, Meyer D, Wu C, Shen WH (2005). Prevention of early flowering by expression of FLOWERING LOCUS $C$ requires methylation of histone H3 K36. Nat Cell Biol 7: 1256-1260.

Zhu Y, Dong A, Meyer D, Pichon O, Renou JP, Cao K et al. (2006). Arabidopsis NRP1 and NRP2 encode histone chaperones and are required for maintaining postembryonic root growth. Plant Cell 18: 2879-2892.

Zilberman D, Coleman-Derr D, Ballinger T, Henikoff S (2008). Histone H2A.Z and DNA methylation are mutually antagonistic chromatin marks. Nature 456: 125-129. 